\title{
Synchronous colorectal liver metastases: timing of resection and patterns of referral
}

\author{
Fiona Hand, Stephen J. Wigmore \\ Department of Clinical Surgery, Royal Infirmary of Edinburgh, Edinburgh, UK \\ Correspondence to: Fiona Hand. Department of Clinical Surgery, Royal Infirmary of Edinburgh, Little France Crescent, Edinburgh EH16 4SA, UK. \\ Email: fionahand@rcsi.ie. \\ Provenance and Peer Review: This article was commissioned by the Editorial Office, Hepatobiliary Surgery and Nutrition. The article did not undergo \\ external peer review. \\ Comment on: Howard C, Clements TW, Edwards JP, et al. Synchronous colorectal liver metastases: a national survey of surgeon opinions on \\ simultaneous resection and multidisciplinary cooperation. Hepatobiliary Surg Nutr 2018;7:242-50.
}

Submitted Sep 26, 2019. Accepted for publication Oct 10, 2019.

doi: $10.21037 /$ hbsn.2019.10.13

View this article at: http://dx.doi.org/10.21037/hbsn.2019.10.13

There remain no consensus guidelines on the optimum surgical strategy for the management of synchronous colorectal liver metastases in spite of a number of published reviews and meta-analyses $(1,2)$. In their paper, Howard et al. describe the 'real world' referral patterns and resection pathways of Canadian surgeons for this challenging patient cohort (3). This is a timely and interesting area for study. Data was generated from an online survey sent out to all surgeons in Canada. Responses were received from 58 surgeons but 6 responses were inadequate for analysis leaving 52 surgeon responses included for analysis. The study does not indicate the total number of surgeons who were invited to participate and so the proportional response rate is unknown. Like all survey based-studies, the small number of respondents included does raise the question of inherent selection bias which cannot be discounted. In addition, almost all included surgeons had access to hepatobiliary services, with over half reporting access to hepatobiliary surgeons within their own institutions, such availability would undoubtedly affect decision making in this setting. Providing information around the nature and scope of general surgical and surgical oncology training in Canada would have been useful in understanding the likely experience of surgeons. Nonetheless this paper raises some interesting points in the management of patients with synchronous colorectal liver metastases.

The majority of the study population (94\%) were in agreement that combined resection has a role in the management of synchronous disease, with a significant proportion of responding colorectal surgeons (67.9\%) participating in combined resections. Hepatic metastases remain the chief determinant of mortality in patients with colorectal liver metastases, yet just $60 \%$ of respondents regularly referred synchronous cases for preoperative discussion with HPB surgeons despite the aforementioned ease of access to HPB services amongst the group. In addition, just over half of responding surgeons would consider a role for "liver-first" approach to resection. Perhaps this is reflective of another finding in this study whereby $60 \%$ of responding colorectal surgeons believe they could predict resectability of liver resections.

In asymptomatic patients presenting with synchronous disease, colorectal surgeons were more likely to refer to medical oncology in the first instance $(59.3 \%)$ rather than seek a hepatobiliary opinion (33.3\%). However, caution must be taken with this approach as data has shown the perception of resectability varies greatly between medical oncologists and hepatobiliary surgeons in patients with liver metastases (4). For symptomatic patients, a minority of surgeons would seek a hepatobiliary opinion, instead opting for operative resection of the primary tumour which was the favoured approach for both colorectal and general surgeons (74.1\% and $83.3 \%$ respectively). In this era of patient-centred care it is slightly disappointing that the paper did not really explain the influence of patient choice on surgical decision-making.

Vast strides have been made in the last decade in expanding the criteria for resectability of colorectal liver metastases. Surprisingly however, $55 \%$ of surgeons in this study still felt bilobar liver metastases were the chief deterrent to surgical resection. Similar findings were 
reported in a survey by Quereshi et al. who found bilobar metastases a significant obstacle to resection for colorectal surgeons, in contrast to the hepatobiliary surgeons surveyed in the same study (5). Furthermore, medical comorbidities and advancing age were cited as barriers to resection despite published data to the contrary $(6,7)$.

Perhaps most interestingly, less than a quarter of surgeons surveyed admitted to knowledge of evidence based guidelines on the management of synchronous colorectal liver metastases. This study highlights a number of key points in the management of patients with synchronous disease. There remains a lack of data to guide clinical decision making in this cohort, published studies are in the main retrospective and observational in nature, as the number of these cases increases, surgeons need to be aware of guidelines and strong data to support decision making. This study also highlights a reluctance to engage HPB surgeons early in the patient pathway. The vast majority of the responding surgeons in this survey had access to HPB services, either in their own hospital or as a point of referral, yet regardless of patients presenting symptoms, engaging with HPB services was not considered a priority. There is good evidence that perceived barriers to resectability differ amongst medical oncologists, and surgeons and between surgeons of different disciplines underscoring the need for combined multidisciplinary discussion of patients with synchronous colorectal liver metastases at diagnosis, in order to navigate the optimum clinical pathway. What remains to be discussed includes the relative weighting that should be given to short- and longterm clinical outcomes of two- or single-stage approaches to synchronous colorectal liver metastases when the primary remains in situ compared with patient preference. Patientreported outcome studies in this important clinical area are lacking and would be helpful in guiding future strategies for colorectal, general and HPB surgeons.

\section{Acknowledgments}

Funding: None.

\section{Footnote}

Conflicts of Interest: All authors have completed the ICMJE uniform disclosure form (available at https://hbsn. amegroups.com/article/view/10.21037/hbsn.2019.10.13/coif). The authors have no conflicts of interest to declare.

Ethical Statement: The authors are accountable for all aspects of the work in ensuring that questions related to the accuracy or integrity of any part of the work are appropriately investigated and resolved.

Open Access Statement: This is an Open Access article distributed in accordance with the Creative Commons Attribution-NonCommercial-NoDerivs 4.0 International License (CC BY-NC-ND 4.0), which permits the noncommercial replication and distribution of the article with the strict proviso that no changes or edits are made and the original work is properly cited (including links to both the formal publication through the relevant DOI and the license). See: https://creativecommons.org/licenses/by-nc-nd/4.0/.

\section{References}

1. Gavriilidis P, Katsanos K, Sutcliffe RP, et al. Simultaneous, Delayed and Liver-First Hepatic Resections for Synchronous Colorectal Liver Metastases: A Systematic Review and Network Meta-Analysis. J Clin Med Res 2019;11:572-82.

2. Gavriilidis P, Sutcliffe RP, Hodson J, et al. Simultaneous versus delayed hepatectomy for synchronous colorectal liver metastases: a systematic review and meta-analysis. HPB (Oxford) 2018;20:11-9.

3. Howard C, Clements TW, Edwards JP, et al. Synchronous colorectal liver metastases: a national survey of surgeon opinions on simultaneous resection and multidisciplinary cooperation. Hepatobiliary Surg Nutr 2018;7:242-50.

4. Choti MA, Thomas M, Wong SL, et al. Surgical Resection Preferences and Perceptions among Medical Oncologists Treating Liver Metastases from Colorectal Cancer. Ann Surg Oncol 2016;23:375-81.

5. Qureshi MS, Goldsmith PJ, Maslekar S, et al. Synchronous resection of colorectal cancer and liver metastases: comparative views of colorectal and liver surgeons. Colorectal Dis. 2012;14:e477-85.

6. Schiergens TS, Lindenthaler A, Thomas MN, et al. Timedependent impact of age and comorbidities on long-term overall survival after liver resection. Liver Int 2016;36:1340-50.

7. Dedinská I, Laca L, Miklušica J, et al. Complications of liver resection in geriatric patients. Ann Hepatol 2017;16:149-56.

Cite this article as: Hand F, Wigmore SJ. Synchronous colorectal liver metastases: timing of resection and patterns of referral. HepatoBiliary Surg Nutr 2020;9(2):242-243. doi: 10.21037/hbsn.2019.10.13 